\title{
Adjustment in Instructional Techniques through Formative Assessment Data and
}

\author{
Evidence \\ * Mrs. Salima Begum, PhD Scholar \\ ** Dr. Munazza Ambreen, Assistant Professor \\ *** Dr. Nasrullah Khan, Assistant Professor (Corresponding Author)
}

\begin{abstract}
This paper highlights the significance of formative assessment data in adjusting instructional techniques in the classroom that lead to improving students' learning. The study was conducted in a qualitative paradigm using a case study approach. Associate Degree in Education (ADE) Program, instructors, and students were the research participants in this study. Four data collection methods including document analyses, interviews, classroom observations, and focused group discussions. The use of different data collection methods enabled the researcher to triangulate data to ensure the validity and reliability of the study. The thematic analysis approach was used to analyze data. The study presented important findings which indicated that there was a strong connection between formative assessment strategies and instructional design. It was evident that the instructor recorded formative assessment data, systematically analyzed, categorized, and then drawn conclusions about instructional design as well as students learning outcomes. Instructor planned daily lessons with a strong alignment of formative assessment strategies and students learning. The study revealed that the implementation of different formative assessment strategies improved students' communication, reading skills, writing skills, presentation, critical thinking, and problem-solving ability.
\end{abstract}

Keywords: Teaching, Instructions, Techniques, Formative Assessment, Adjusting Instructions Introduction

Formative assessment was an essential part of the teaching and learning process through which students' learning evidences were gathered, analyzed, categorized, decisions were made, and adapted instructional design based on the collected data from the classroom. This paper highlighted the processes of instructional adjustment based on formative assessment data by an instructor in the Associate Degree in Education Program in the context of Pakistan. The study focused on the significant aspect of formative assessment data collection processes and recording, analyzing, categorizing, decision making that lead to adjustment in instructional techniques. The research paper argues that effective and efficient use of formative assessment data in improving instructional design was pivotal at the classroom level. It indicated that well-planned data recording, analyses, categorizing, decision making, and adjusting instructions were very important to identify and address students learning needs to improve their learning outcomes over time in the classroom.

Objectives of the Study

1. To examine the relationship between formative assessment and instructional design.

2. To know about the use of formative assessment and students learning.

\section{Study Questions}

1. What is the relationship, in the Associate Degree in Education Program use in formative assessment strategies and instructional techniques?

2. How these strategies adjust instructional techniques in classroom assessment?

\section{Literature Review}

Formative assessment was looking for presenting explicit goals and set criteria to the students to advance their learning outcomes by examining the existing position of learning related to the set 
criteria and goal (Andrews, et al., 2018; Ong, Csbsnsag, \& Sacolles, 2016). The effective formative assessment involves knowing about students' intended outcomes, current performance, steps to address gaps, and engaging them in the learning process (Panadero, Andrade, \& Brookhart, 2018; James, 2017; Grob, et al, 2017).

According to the modern paradigms, assessment should not be an endpoint in the learning episode rather it should be a continuous part of the learning process. As per these paradigms such as constructivism of learning, students learning was influenced by social connections, interactions, and the positioned nature of cognition (Shatri \& Zabeli, 2018; Yüksel \& Gündüz, 2017). This philosophy expects students to actively participate in learning processes and construct new knowledge based on previous knowledge (James, 2017; Clark, 2015).

As per, Grob, et al., (2017) the process of immediate use of formative assessment evidence to make appropriate modifications in instructions, differentiate, and address students' learning need to improve their progress. Researchers defined formative assessment, a common and cooperative assessment of learners' growth and knowledge to categorize students learning requirements and modify teaching/learning processes to address students' learning needs by providing prompt feedback on their progress and performance (Lomask, et al., 2018; Wong, et al., 2018; Ogange, et al., 2018; Shute and Rahimi, 2017).

Formative assessment was a strategy which contributes to revise learning by identifying students' learning gaps and providing proper feedback to address the learning gaps (Watling \& Ginsburg, 2019). Assessment was a purposeful activity, through which teachers were collecting classroom teaching/learning evidence, analyzed those evidences to revise students learning and improve instructions by using appropriate teaching techniques (James, 2017)

Collecting and analyzing concrete evidences from the classroom to understand students' knowledge, performance to restructure instructional design. These evidences were collected through a need's assessment test, placement test, or pre-test, and based on this collected information teachers were adjusting instructions to address students learning needs (Wiliam, 2017). Proficient and skillful teachers find out what students already know and use previous information and skills as a foundation to construct new knowledge and skills (Chappuwas, Commodore, \& Stiggins, 2017). Teachers can determine how well student learning matches anticipated outcomes for a course by systematically, collecting, analyzing, and interpreting students learning evidences to adjust instructions (Melanie, et al, 2017). Additionally, teachers were collecting information through feedback and this information supports teachers to improve their instruction (Janssen \& Rowen, 2016).

Grob, et al, (2017) identified four useful practices in which formative assessment assists students' learning in self-directed activities such as, "firstly, the clarification of the intentions of learning assessment criteria. Secondly, the diagnoses of students' level of achievement as a base for subsequent actions. Thirdly, the provision of feedback to the individual student to decide on the next steps in learning. Lastly, the fostering of self-regulated learning abilities."

Appropriate formative assessment methods help learners in independent activities that included students' self-assessment and peer assessment. Teacher's written feedback on students work to inform students about their learning progress (Adkins, 2018). Formative assessment was providing an opportunity for teachers and students to assess their learning. While going through the processes of formative assessment students were observing, predicting, explaining, and arguing to justify their responses and conclusions through peer and self-assessment (Chng \& Lund, 2018).

Assessment derives student learning because in assessment strategies educators were defining the process of how students need to think and learn. Assessment strategies were defining, how students have to learn, what they have to learn, and how much time was needed to accomplish the assigned task in a unit or course of study (Adkins, 2018; Wiliam, 2017).

Assessment data was equally important for students that effective assessment strategies provide information to the students about their progress, what they know, what they need to know about a theme or subject, and what were the fruitful processes they have to go through to enhance their learning (Lomask, Crwasmond, \& Hacker, 2018). Assessment needs to be linked with instructional activities, content, and the nature of thinking of students in the classroom. In assessment when teachers were providing constructive feedback to the students, it supports them to recognize and 
classify their learning strengths and weaknesses and finding alternative solutions to overcome their weak areas (Braund \& DeLuca, 2018).

\section{Methodology}

The researcher used a qualitative paradigm, to study formative assessment practices in a natural setting and attempt to make sense of, or interpret phenomena (Gall, Borg, \& Gall, 1996). In a qualitative paradigm researcher used a case study approach to study formative assessment practices in depth (Dooley, 2002). The research participants of this study were an instructor of the College of Education teaching to ADE. Eight ADE students were selected for focused group discussion. In the data collection process researcher analyzed instructor lesson plans and assessment sheets to understand the connection between her stated views, planning, and implementation of both instructional and formative assessment strategies. Research conducted four interviews with instructor and video recorded 46 classroom teaching to witness practices of formative assessment strategies. Focused group discussions with students were made to record students' viewpoints and identify adjustment of instructional design. The researcher applied the thematic analyses approach using four phases to develop themes from transcribed data and wrote a research report, such as 'initializing', 'construction', 'rectification', and 'finalization. The researcher also applied the strategy of 'Pattern matching' to ensure the internal validity of data.

\section{Findings}

- $\quad$ The study revealed that formative assessment data has a direct relation with the planning process. The data indicated that formative assessment data-guided instructor to reflect on the contribution of lesson's activities in promoting students' learning as mentioned by the instructor in her interview, "formative assessment strategies of today can be beneficial for tomorrow's planning because it would reflect those strategies.

- $\quad$ Formative assessment enabled teacher for analyzing and reflecting on the suitability of strategy with the topic": It also endorsed by Reeves (2018) that data utilization for development involves a cycle of gathering and understanding data, inferring, making ideas on possible responses, solutions, making suitable amendments for improvement, monitoring and investigating whether changes resulted in development.

- Implementing formative assessment activities teacher was analyzing students learning evidences and continue those strategies which were fruitful and change those strategies which were considered challenging to improve students' learning outcomes.

- Classroom observations also validated that instructor was changing her instructional techniques based on the recorded data. She was analyzing, categorizing, decision making, and adjusting her instructional techniques daily. In document analysis, it was discovered that the instructor changed her formative assessment strategies and adjusted her instructional techniques.

- The study indicated that formative assessment data not only identify the contribution of instructional and assessment strategies but also guide instructor to make an appropriate revision in the lesson and update learning activities that were significantly important for students as mentioned by research participant in her interview, respondent stated that analyzing and reflecting on the previous lesson always helpful in teaching.

- Classroom observations also confirmed that the instructor was observing students learning progress, participation and she was recording students learning by using a checklist. Documents analysis also established that the instructor revised activities for her classroom accordingly. Similarly, students verified the same techniques applied by their instructors. They stated that if they faced any difficulty in an activity then the instructor changed the activity and implemented another, it was also observed by (Brink and Bartz, 2018) that formative assessment need to be observed as a continuous process, with learners being provided several chances to perform what they knew. By implementing formative assessment teachers can recognize the diverse learning needs of learners and adapt instructions to address them. Assessment needs to be concerned about learners' content knowledge and skills. If learners will take ownership of the assessment results, those results were supporting learners to improve their learning and achievement. 


\section{Discussion}

The study identified that providing constructive and positive feedback improved students' learning in the classroom. It was found from the data that the instructor provided feedback to students based on formative assessment information. She particularly highlighted positive aspects of students' learning and mentioned grey areas where students had to focus their energy and time. Constructive feedback was well received by students and appreciated the instructor's approach that provided opportunities for students to address their learning gaps. Furthermore, the instructor said, "through formative assessment, students get the opportunity to present their tasks and ideas logically and systemically and learn to respond to questions from teachers and colleagues. They received individual feedback on their ideas and presentations from the instructor and their colleagues. They got the opportunity to complete their task individually by using their critical thinking skills and assess their peer work, provide feedback with suggestions and alternatives to overcome their need improvement were expressed their views that formative assessment learners were oriented with multiple strategies and they were getting opportunity to assess their peers work and their work, teach to their friends, discussing ideas in small and large groups, present their work in small and large groups. During participation in these activities, learners were getting feedback from their facilitators to fill their learning gaps and improve their learning. While responding to the provided feedback learners were answering three main questions, where I am now? Where I need to be? How can I get there? And what was my next target?

Likewise, the instructor articulated, "informative assessment strategy, students have options to present their learning as per their learning style because teachers revise assessment strategy according to student's needs. The teacher was encouraging us that we were speaking well and do more hard work to share our learning with the whole class. Informative assessment strategies teacher was creating different learning opportunities for us i.e. write, read, listen, speak, and reflect on our learning by using two minutes of reflection, two minutes essay, and one-minute fluency. The teacher was also involving us in peer assessment and self-assessment and these strategies helping us to improve our confidence and critical thinking skills. Learners were getting the opportunity to provide feedback to their fellows where they were thinking critically to identify strengths and weaknesses of their fellows' work. These practices enhance students' communication, articulation, and critical thinking skills. Numerous sources confirm that formative assessment meaningfully influences learners learning when delivered using effective feedback.

The study also found that formative assessment strategies improved students' motivation, communication, reading, writing, presentation, thinking, problem-solving skills, and confidence by helping them to recognize their learning strengths and need improvement areas. In these strategies all students were accountable to complete the assigned task and present in the classroom because after completion of the task teacher was randomly asking any student to present the assigned task in the classroom. Additionally, Adkins (2018) also expressed his views that formative assessment was helping students to develop and enhance their level of motivation to learn new knowledge and skills in the classroom. Different strategies and activities of formative assessment was developing selfconfidence, motivation, positive, intelligent behavior, and create a positive feeling about learning. Informative assessment three steps were very important, such as firstly setting goals and standards for learning. Secondly, comparing the actual learning of learners with set goals and standards and thirdly, engages learners in suitable actions which leads to improve students learning by filling the identified learning gaps. Classroom observations also witnessed that instructors provided multiple opportunities for learners in the classroom to learn and express their learning with diverse strategies by adjusting instructions. Instructors sometimes ask students to think about the concept and collect their previous information and share it with the teacher and the whole class. These activities actively engaged students and their motivation was worth observing. The instructor shared her experiences in the interview and stated, "I am creating multiple learning opportunities for students in the classroom by applying different formative assessment strategies by adjusting instructions. Students were enthusiastically participating in these strategies because multiple strategies were addressing their diverse learning needs. Feedback was supporting learners to realize their learning gapes and mistakes and it motivates learners to improve their desire for learning and discourage the give up habit it was also identified by (Taylor, 2018). The study also indicated that formative assessment evidence provide 
an opportunity to the instructor to group students as per their learning abilities as mentioned by research participant, "while executing formative assessment strategies they identifying low performing students and giving additional support to those students to bring them at the level of other students. Classroom observations also validated that instructors engaged students in different formative assessment strategies such as pair work, one-minute fluency etc. She also recorded students' learning, confidence level, attitude, communication, participation, and cooperation by using formative assessment tools. Formative assessment was a fundamental aspect of the process which feeds data into instructional design and influences teachers' decision making about instructions that they must adjust instructions for meaningful learning. Informative assessment teachers were assessing students' capabilities, knowledge, skills, competencies, and gathering data about students learning evidences (Alotaibi, 2019).

\section{Conclusion}

Formative assessment was unique from other forms of assessment because through formative assessment teachers and students were implementing activities in a collaborative manner where teachers were facilitating, identifying, and addressing students learning needs by adjusting instructions. Students were working as teacher's partners in the classroom sharing their learning, inquiring concepts, and clarifying ideas by asking questions to improve their learning. Informative assessment teachers were collecting students learning evidence, analyzing, categorizing, and decision making, and adjusting instructions to improve students learning. Through formative assessment, teachers can create effective learning opportunities for students to perform their knowledge and skills, identify their strengths, and need improvement, to take proper and timely decision to improve their learning. The role of teachers was to inform students about their progress continuously, where they were and how can they achieve their objectives. Whatever strategy of formative assessment teachers adopt, the main goal was eliciting the gaps in students learning and collect the evidence of students learning, providing feedback, and engage students in fruitful learning activities were common techniques of formative assessment.

\section{Recommendations}

1. The teacher may keep the record of formative assessment of the learners and apply its remedial measures in the class when needed in a specific situation.

2. The relationship between formative assessment and teaching strategies may be maintained for each student so that it provides guidelines for the teacher in evaluation.

3. There may be a written record about the assessment used by the teacher in the classroom and it can be examined with the teaching practices to maintain class discipline and students' interests.

\section{References}

Adkins, J. K. (2018). Active learning and formative assessment in a User-Centered design course. Information Systems Education Journal (WASEDJ), 16 (4), 34-40. http://wascap.info.

Alotaibi, K. A. (2019). Teachers' perceptions of factors influence the adoption of formative assessment. Journal of Education and Learning, 8(1), 74-86. DOI:10.5539/jel. v8n1p74

Andrews, M., Brown, R., \& Mesher, L. (2018). Engaging students with assessment and feedback: Improving assessment for learning with students as partners. Practitioner Research in Higher Education: Special Assessment, 11 (1), 32 - 46. https://insight.cumbria.ac.uk/id/eprint/3840.

Braund, H., \& DeLuca, C. (2018). Elementary students as active agents in their learning: An empirical study of the connections between assessment practices and student's metacognition. Australian Educational Researcher, 45 (1), 65-85. https://doi.org.

Brink, M., \& Bartz, D. E. (2018). Effective use of formative assessment by high school teachers. Practical Assessment, Research and Evaluation, 22(8), 2-10.

Chappuwas, S., Commodore, C., \& Stiggins, R. (2017). Balanced assessment systems: Leadership, quality, and the role of classroom assessment. Thousand Oaks, CA: Corwin.

Chng, L., \& Lund, J. (2018). The impact of formative assessment on the success and response rate in a 6th-grade Physical education Badminton unit. International Journal of Kinesiology in Higher education. 1-11. https://doi.org/10.1080/24711616.2018.1509680

Clark, I. (2015). Formative assessment: Translating high-level curriculum principles into classroom practices. The Curriculum Journal, 26 (1), 91-114. 
Dooley, L. M. (2002). Case study research and theory building. Advances in Developing Human Resources, 4(3), 335-354.

Grob, R., Holmeier, M., \& Labudde, P. (2017). Formative assessment to support students' competences in inquiry-based science education. Interdisciplinary Journal of Problem-Based Learning, 11(2). https://doi.org/10.7771/1541

Janssen, A., \& Rowen, R. (2016). Purpose, meaning, and alignment: Dual frameworks to scaffold understanding and design of assessment to enhance the student and teacher experience. Journal of Academic Language and Learning, 10 (1), 191- 205.

Lomask, M., Crwasmond, D., \& Hacker, M. (2018). Using teaching portfolios to revise curriculum and explore instructional practices of technology and engineering education teachers. Journal of Technology Education, 29 (2), 54 - 72.

Melanie, A., DiLoreto, A. M., Pellow, C., David, L., \& Stout, L. D. (2017). Exploration of conceptions of assessment within High-Stake U.S. culture. International Journal of Learning, Teaching and Educational Research, 16 (7), 1- 9.

Ogange, B. O., Agak, J. O., Okelo, K. O., \& Kiprotich, P. (2018). Student perceptions of the effective formative assessment in an online learning environment. International Council for Open and Distance Education, 10 (1), 29-39.

Ong, E., Cabansag, H., \& Sacolles, H. (2016). Formative assessment as scaffolds to increase mathematics achievement of grade 11 students. Unpublished Doctoral Thesis, De La Salle University, Manila.

Panadero, E., Andrade, H., \& Brookhart, S. M. (2018). The Australian Educational Researcher, 45 (1), 13- 31. DOI: 10.1007/s13384- 018- 0258- y.

Reeves, T. (2018). School-level and other differences in Illinowas teachers' use of data to inform instruction. Mid-western Educational Researcher, 29 (4), 332-354.

Shatri, Z. G., \& Zabeli, N. (2018). Perceptions of students and teachers about the forms and student self-assessment activities in the classroom during the formative assessment. Journal of Social Studies Education Research, 9 (2), 28 - 46. www.jsser.org

Shute, V. J., \& Rahimi, S. (2017). Review of computer-based assessment for learning in elementary and secondary education. Journal of Computer Asswasted Learning, 33 (1), 1- 19.

Taylor, K. (2018). Culturally relevant writing pedagogy: An Investigation of assessments, feedback, and equity. Unpublished Doctoral Dwassertation, University of Illinowas at Chicago, Chicago. http://hdl.handle.net/10027/22676

Watling, C. J., \& Ginsburg, S. (2019). Assessment, feedback, and the alchemy of learning. Medical Education, 53, 76-85. DOI: $10.1111 /$ medu.13645

Wiliam, D. (2017). Assessment for learning: Meeting the challenge of implementation. Assessment in Education: Principles, Policy, and Practice, 1-4.

Wong, T. K. Y., Tao, X., \& Konwashi, C. (2018). Teacher support in learning: Instructional and appraisal support concerning math achievement in Educational Research, 28 (1), 202 - 219.

Yükselii, S. H., Gündüz, N. (2017). Formative and summative assessment in higher education: Opinions and practices of instructors. European Journal of Education Studies, 3 (8), 336- 355. DOI:10.5281/zenodo.832999. 